\title{
Ribose Metabolism and Nucleic Acid Synthesis in Normal and Glucose-6-Phosphate Dehydrogenase-deficient Human Erythrocytes Infected with Plasmodium falciparum
}

Eugene F. Roth, Jr., Ruth M. Ruprecht, Seymour Schulman, Jerome Vanderberg, and Julie A. Olson Polly Annenberg Levee Division of Hematology, Mount Sinai School of Medicine, New York 10029; Dana Farber Cancer Institute, Boston, Massachusetts 02115; Division of Hematology, Albert Einstein College of Medicine, Bronx, New York 10461; Department of Medical and Molecular Parasitology, New York University School of Medicine, New York 10016

\begin{abstract}
The metabolism of pentose-phosphate was investigated in Plasmodium falciparum-infected normal and glucose-6-phosphate dehydrogenase (G6PD)-deficient human red blood cells in vitro. 5'-Phosphoribosyl-1-pyrophosphate (PRPP) content of infected normal red blood cells was increased 50-60-fold at the parasite trophozoite growth stage over that of uninfected cells. The PRPP increment in infected G6PD-deficient cells at comparable stage and parasitemia was only $\mathbf{4 0 \%}$ of the value in normal infected cells. Red blood cell PRPP synthetase activity did not change during the growth cycle of the parasite and was similar in both normal and G6PD-deficient cells. Reduced glutathione (GSH) content of G6PD-deficient cells under conditions of culture fell to low or undetectable levels. These low levels of GSH were shown to inhibit the function of red blood cell PRPP synthetase, which requires GSH for full activity. Measurements of the incorporation of $1-{ }^{14} \mathrm{C}$ or $6-{ }^{14} \mathrm{C}$ selectively labeled glucose into parasite nucleic acids revealed that in normal infected red cells, $\sim 20 \%$ of the pentose was produced via the oxidation of glucose6-phosphate, whereas in infected G6PD-deficient cells (Mediterranean type), none of the pentose was produced via the oxidative pathway. It is concluded that the low level of reduced GSH found in G6PD deficiency and the resultant partial inhibition of PRPP synthetase together with the missing oxidative pathway for ribose phosphate production can account fully for the reduced parasite growth rate in G6PD-deficient red blood cells described previously. Of these two mechanisms, the predominant one is the impaired PRPP synthetase activity due to low GSH levels in enzyme-deficient red blood cells. The contribution to the ribose-phosphate pool by the hexose monophosphate shunt is relatively minor. A co-existing oxidative stress (which is often hypothesized to mediate the destruction of parasitized red blood cells) is not required to explain growth inhibition in this scheme and does not represent the most straightforward explanation of the data described in this report.
\end{abstract}

\section{Introduction}

Erythrocyte glucose-6-phosphate dehydrogenase (G6PD) ${ }^{1}$ deficiency is a widespread heritable X-linked abnormality which

Address correspondence to Dr. Roth, Division of Hematology, Montefiore Medical Center, 111 East 210th St., Bronx, NY 10467.

Received for publication 23 September 1985.

1. Abbreviations used in this paper: G6PD, glucose-6-phosphate dehydrogenase; GSH, reduced glutathione; PRPP, 5'-phosphoribosyl-1-pyrophosphate.

J. Clin. Invest.

(C) The American Society for Clinical Investigation, Inc. 0021-9738/86/04/1129/07 \$1.00

Volume 77, April 1986, 1129-1135 affects approximately 100 million persons worldwide. The geographical distribution of this enzyme deficiency often coincides with a high incidence of falciparum malaria in the same regions (1). This observation has given rise to a "malaria hypothesis" regarding this and other red blood cell polymorphisms, which states that variant red cells, such as G6PD-deficient red cells, confer a selective advantage against lethal malaria infection, resulting in a high frequency of the variant gene in populations with a high prevalence of malaria. Very strong experimental evidence for the protective effects of sickle hemoglobin (Hb S) has been obtained (2), but until the last decade, most of the evidence supporting the malaria hypothesis for G6PD deficiency remained epidemiological in nature. Recently, in vitro culture of Plasmodium falciparum in G6PD-deficient red cells allowed Roth et al. (3) and Luzzatto et al. (4) to document that inhibition of parasite growth does in fact occur. However, the biochemical mechanisms for the diminished growth rate remains obscure.

G6PD deficiency first came to medical attention as a hemolytic disease secondary to the ingestion of certain pro-oxidant drugs and foods which produced reduced glutathione (GSH) instability. Thus, inhibition of malaria parasite growth was believed to be due to overwhelming oxidant stress and GSH instability, both of which could destroy the host red blood cell and its parasite (5). Indeed, oxidant substances such as menadione (5), alloxan, phenylhydrazine (6), and divicine (7) can be shown to accelerate the destruction of parasitized red blood cells in vitro and/or prolong survival of infected rodents with normal G6PD activity. However, a consistent and pervasive oxidant stress conferring protection in human falciparum malaria has not been demonstrated in natural infections. We therefore have considered other mechanisms for the inhibitory action of G6PD deficiency upon the growth of the malaria parasite.

G6PD is the first enzyme of the hexose monophosphate shunt pathway, which permits the red cell to produce ribose compounds and NADPH in a few simple enzymatic steps. While the fivecarbon sugars probably play a small role in the needs of the uninfected, mature and non-proliferating red cell, they are undoubtedly essential to the parasite, which needs to synthesize a considerable quantity of RNA and DNA in its 48-h red cell growth cycle that yields 16-32 daughter parasites. We hypothesize that a reduction in pentose shunt activity may result in an impaired production of ribose derivatives, including the key ribose metabolite in nucleotide production by either salvage or de novo synthesis, 5-phosphoribosyl-1-pyrophosphate (PRPP). We have therefore focused on the metabolism of PRPP in $P$. falciparum-infected red blood cells. Since PRPP required for nucleic acid synthesis can also be produced by pathways which bypass G6PD, we have estimated the contribution of the shunt in nucleic acid synthesis. In addition to investigating infected red cells, we have used uninfected normal and G6PD-deficient red cells as models for some of the possible metabolic events likely to be encountered during malaria infection. In particular, 
we have considered the effects of a diminished reduced glutathione concentration and oxidant stress on ribose metabolism. We have shown that defective metabolism of ribose compounds does occur in infected G6PD-deficient erythrocytes. However, this phenomenon is primarily caused by low GSH levels rather than by impaired synthesis of ribose phosphate via the defective hexose monophosphate shunt.

\section{Methods}

P. falciparum (FCR-3 strain) was maintained in culture by the method of Trager and Jensen (8). Sedimentation in gelatin was used to concentrate parasitized red cells (9). Parasitemia and stage of growth were determined from Giemsa-stained smears. We obtained blood samples from normal blood bank donors and previously identified G6PD-deficient donors of both the African (G6PD A-) and Mediterranean types. Red cell G6PD enzyme activity was determined as previously described (3).

PRPP determination. PRPP was measured by the radiometric method of Tax and Veerkamp (10) in which PRPP was extracted from infected and control red cells by heat $\left(100^{\circ} \mathrm{C}\right)$. Recovery of a known quantity of PRPP by this method was $85.3 \% \pm 7.6$ (SD). Synchronized cultures were washed three times in phosphate-buffered isotonic saline; hemoglobin concentration was determined by the cyanmethemoglobin method, and red cells were counted on a model Z Coulter counter (Coulter Electronics, Inc., Hialeah, FL). PRPP was determined by using $\left[{ }^{14} \mathrm{C}\right]$ orotate, which in the presence of PRPP is enzymatically converted to orotidylic acid and then decarboxylated to uridylic acid with the evolution of ${ }^{14} \mathrm{CO}_{2}$. The latter is trapped in an organic base (NCS) and mixed with a toluenebased Omnifluor liquid scintillation cocktail and counted. The reactions used in the analysis can be written as follows:

orotate $\left({ }^{14} \mathrm{COOH}\right) \stackrel{\text { PRPP } \rightarrow \mathrm{PP}_{\mathrm{i}}}{\longrightarrow}$ orotidylic acid $\left({ }^{14} \mathrm{COOH}\right) \underset{2}{\rightarrow}$

uridylic acid $+{ }^{14} \mathrm{CO}_{2}$.

Reaction 1 is catalyzed by orotidine-5'-phosphate pyrophosphorylase, and reaction 2 by orotidine-5'-phosphate decarboxylase (both of yeast origin), which were purchased from the Sigma Chemical Co., St. Louis, MO. Purified PRPP (Sigma Chemical Co.) was standardized by this assay and used to construct a standard curve for each set of determinations. A known amount of PRPP was added to an aliquot of the red cell lysate of each run to monitor loss during extraction. Results were expressed as nanomoles of PRPP per gram of hemoglobin or per $10^{9}$ red blood cells.

PRPP synthetase measurements. This enzyme converts ribose-5phosphate to PRPP in the following reaction:

ribose-5-phosphate

$+\mathrm{ATP} \underset{\text { GSH }}{\stackrel{\text { PRP Syntetase }}{\longrightarrow}} 5$ '-phosphoribosyl-1-pyrophosphate + AMP.

The enzyme was measured by a variation of the same method for PRPP as described by Tax and Veerkamp using a PRPP-generating system dependent on PRPP synthetase activity derived from red cell/parasite lysates (10). Exogenous GSH at optimum concentration was always provided for this assay.

Incorporation of specifically radiolabeled glucose into plasmodial nucleic acids. The meaning of this study depends closely on the assumption that $1-{ }^{14} \mathrm{C}$-labeled glucose will lose its radioactive carbon if it is metabolized via the pentose shunt to ribose according to the reactions shown in Fig. 1. If glucose is metabolized to ribose by any other pathway (to be described below), then the $1-{ }^{14} \mathrm{C}$ label is not lost. $\left[6-{ }^{14} \mathrm{C}\right]$ glucose does not lose its label by any of the available pathways because glucose is not metabolized beyond lactate in the red cell-parasite system (11), as no complete tricarboxylic acid cycle is present. Thus, a study of different labeling patterns of parasite nucleic acids starting from $1-{ }^{14} \mathrm{C}$ - or $6-{ }^{14} \mathrm{C}$ labeled glucose can be used to determine the contribution of the hexose monophosphate shunt pathway to nucleic acid ribose.

Parasites were inoculated into normal and G6PD-deficient (Mediterranean type) red cell suspensions and allowed to proceed through one growth cycle. The infected cells were enriched by gelatin sedimentation and reinoculated into fresh red cells of the same G6PD type so that contamination of the G6PD-deficient cells with normal cells from the original inoculum containing normal red cells was avoided. After $24 \mathrm{~h}$, the medium was replaced with fresh culture medium and the cultures (now at the ring stage) were divided into two $10-\mathrm{ml}$ Petri dishes. $50 \mu \mathrm{Ci}$ $\left[1-{ }^{14} \mathrm{C}\right]-$ or $\left[6-{ }^{14} \mathrm{C}\right]$ glucose (New England Nuclear, Boston, MA) were added to each dish. The final specific activity for each label was $5 \mathrm{mCi} /$ mol glucose. It was necessary to use $50 \mu \mathrm{Ci} / 10 \mathrm{ml}$ cell suspension because preliminary experiments had demonstrated that $\sim 99 \%$ of the glucose is converted to lactic acid and other low molecular weight compounds which are discarded with cell washing and fractionation. Each 10-ml aliquot was further separated into two 5-ml Petri dishes at an hematocrit of $5 \%$ with a $5 \%$ parasitemia which yielded a total of $\sim 2.75 \times 10^{8}$ parasites exposed to either C-1 or C-6 labeled glucose. After $24 \mathrm{~h}$ of incubation

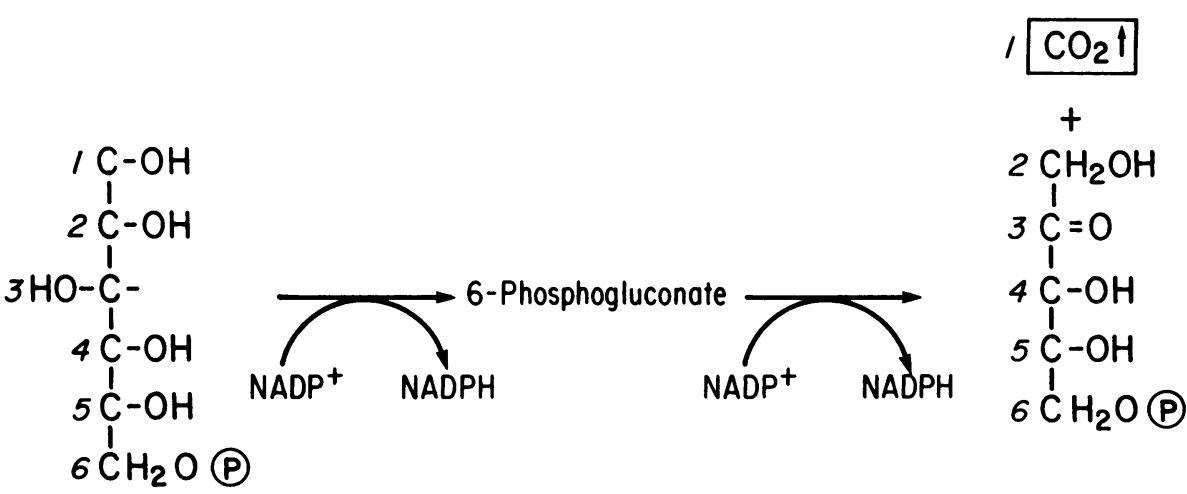

Glucose- 6 phosphate<smiles>[3H][3H]</smiles>

Embden-Meyerhof

Glycolytic pathway

-Non-oxidative pathways to ribose-5-phosphate

Ribulose-5-phosphate
$\mathbb{P}=$ Phosphate
Figure 1. Metabolic scheme indicating the pathways for the metabolism of glucose-6-phosphate in the $P$. falciparuminfected erythrocyte. The scheme shows that the $\mathrm{C}-1$ carbon of glucose is removed as $\mathrm{CO}_{2}$ only when glucose-6-PO is metabolized via the hexose monophosphate shunt. The other pathways for the synthesis of ribose-5-phosphate are derived from the main glycolytic pathway and result in the incorporation of the C-1 carbon in ribose although not necessarily as the first carbon of the pentose. An intact citric acid cycle is not present. 
with the radioactive glucose, the cells were washed in serum-free medium and lysed in $0.1 \%$ saponin in medium without serum. The disrupted cells were sedimented in siliconized glass tubes at $3,000 \mathrm{~g}$ for $15 \mathrm{~min}$, which resulted in a pellet containing parasites, hemozoin pigment, and membrane fragments. The pellets were frozen with 5,000 units of heparin at $-80^{\circ} \mathrm{C}$ until extraction of the nucleic acids was performed.

Extraction of nucleic acids. The pellets were suspended in $0.1 \mathrm{M}$ Tris (pH 7.4), EDTA (12.5 mM), with $1 \%$ SDS to which had been added RNAsin $(2,000 \mathrm{U} / \mathrm{ml}$ ), a placental RNAase inhibitor (Biotech, Inc., Madison, WI). Proteinase $\mathrm{K}$ was added to a final concentration of 500 $\mu \mathrm{g} / \mathrm{ml}$, and the samples were incubated at $37^{\circ} \mathrm{C}$ for $1 \mathrm{~h}$. Following extraction with a 1:1 mixture of phenol/chloroform, and then, with chloroform/isoamyl alcohol (24:1), the nucleic acids were alcohol precipitated. The pellet was dissolved in diethyl-pyrocarbonate-treated $5 \mathrm{mM}$ EDTA, and the absorbance determined at 260 and $280 \mathrm{~nm}$. The nucleic acids were highly purified as shown by the $260: 280$ ratio of 2.2 . A portion of this material was precipitated with $5 \%$ cold trichloroacetic acid in the presence of nonradioactive carrier DNA. The precipitate was trapped on a nitrocellulose filter and counted in a Beckman liquid scintillation spectrometer (Beckman Instruments, Fullerton, CA). Another aliquot was treated with RNase A (boiled to remove DNase activity) for $30 \mathrm{~min}$ at $37^{\circ} \mathrm{C}$, and re-extracted first with chloroform/phenol and then with chloroform/isoamyl alcohol, and finally reprecipitated with ethanol. The purity of each preparation was determined by gel electrophoresis followed by ethidium bromide staining. The specific activity for the total nucleic acid preparation was determined on five separate aliquots and expressed as counts per minute per microgram nucleic acid (mean $\pm \mathrm{SD}$ ). Differences in specific activity were analyzed by the $F$ test and Student's $t$ test with a correction for small sample size (12).

The role of GSH in PRPP synthesis of intact cells. Normal and G6PDdeficient human red blood cells were obtained in heparin. The buffy coat was removed by aspiration, and the cells were suspended in isotonic glycyl-glycine-phosphate buffer, pH 7.4 (13), and incubated with chlorodinitrobenzene which, because of the action of glutathione- $S$-transferase, removes red cell GSH and no other sulfhydryl-containing material (14). Residual GSH was measured by the method of Beutler (15). The cells were washed three times in the same buffer and incubated at $37^{\circ} \mathrm{C}$, with $5 \mathrm{mM}$ inosine for $30 \mathrm{~min}$. In the presence of red blood cell nucleoside phosphorylase inosine is split into ribose-1-phosphate and hypoxanthine (16). In the presence of PRPP synthetase and suitable cofactors such as GSH, $\mathrm{Mg}^{++}$, and ATP, ribose-1-phosphate (after conversion to ribose5-phosphate by red cell phosphoglucomutase) is converted to PRPP (17). When GSH-depleted red cells are subjected to this procedure, the study becomes a test of the requirement of PRPP synthetase for GSH. It should be noted that PRPP synthetase, but not nucleoside phosphorylase or phosphoglucomutase is dependent on GSH as a cofactor $(16,17)$.

Effect of ascorbate metabolic stress on PRPP synthesis. Normal and G6PD-deficient erythrocytes from freshly drawn heparinized blood were washed; the buffy coat was removed by aspiration, and the cells were suspended at a packed cell volume of $20 \%$ in glycyl-glycine phosphate buffer, $\mathrm{pH} 7.4$, at $37^{\circ} \mathrm{C}$ with $10 \mathrm{mM}$ glucose. Neutralized sodium ascorbate was added to one portion of the cell suspension (final concentration, $25 \mathrm{mM}$ ) as a source of $\mathrm{H}_{2} \mathrm{O}_{2}$, and the cells were incubated for $1 \mathrm{~h}$. At the end of this incubation, the cells were processed for GSH and PRPP determinations as described above. In all of the model experiments with uninfected red blood cells, removal of the white cell-platelet portion by aspiration of the buffy coat or by passage through a column of alpha crystalline cellulose (18) yielded similar results.

GSH content of $P$. falciparum-infected erythrocytes. Malaria cultures were established as described above in normal or in G6PD-deficient erythrocytes. The infected cells were concentrated by gelatin sedimentation, and washed twice in saline. GSH was determined by the method of Beutler (15). Results were expressed as micromoles of GSH per gram of hemoglobin (measured by the cyanmethemoglobin method), because the cyanmethemoglobin method is not sensitive to the conversion of a portion of the hemoglobin into hemozoin. (This phenomenon, which is related to the inability of the parasite to catabolize the heme moiety, will be the subject of separate report.)
Table I. PRPP Content of G6PD-deficient and Normal Human Erythrocytes Infected In Vitro with P. falciparum

\begin{tabular}{llll}
\hline & Parasitemia & $\begin{array}{l}\text { PRPP } \\
(n m o l / g ~ H b)\end{array}$ & $\begin{array}{l}\text { PRPP }(\mathrm{nmol} / \\
\left.10^{9} \text { red cells }\right)\end{array}$ \\
\hline & $\%$ & & \\
& & $17.1 \pm 8.6$ & $0.55 \pm 0.28$ \\
$\begin{array}{l}\text { Normal controls (5)* } \\
\text { G6PD- Controls (3) }\end{array}$ & - & $14.1 \pm 1.3$ & $0.46 \pm 0.09$ \\
$\begin{array}{l}\text { Normal RBCs } \\
\quad \text { + Rings (5) }\end{array}$ & $21 \pm 6$ & $16.6 \pm 8.6$ & $0.54 \pm 0.19$ \\
$\begin{array}{l}\text { G6PD- RBCs } \\
\quad+\text { Rings (3) }\end{array}$ & $16 \pm 3$ & $12.6 \pm 3.8$ & $0.41 \pm 0.11$ \\
$\begin{array}{l}\text { Normal RBCs } \\
\quad+\text { Trophozoites (5) }\end{array}$ & $18 \pm 7$ & $211.6 \pm 44.8$ & $6.55 \pm 1.49$ \\
$\begin{array}{l}\text { G6PD- RBCs } \\
\quad+\text { Trophozoites (3) }\end{array}$ & $19 \pm 3$ & $74.7 \pm 15.1 \ddagger$ & $2.59 \pm 0.57 \ddagger$
\end{tabular}

RBC, red blood cell. Numbers in parentheses equal number of samples.

* Values for freshly drawn red cells are $5.56 \pm 0.72 \mathrm{nmol}$.

$\ddagger P<0.001$, normal vs. G6PD ${ }^{-}$.

\section{Results}

PRPP content. Infection of either normal or G6PD-deficient erythrocytes with $P$. falciparum did not provoke an instantaneous increase in PRPP (Table I). Up to the ring stage of parasite growth (the first $24 \mathrm{~h}$ ), there was no increase in PRPP content. In the second 24-h period, which includes the trophozoite-schizont stages, there was an explosive increase in PRPP content of normal infected cells. If extrapolated to $100 \%$ parasitemia, the increment in PRPP content is 56 times baseline levels. An increment in the PRPP content of infected G6PD-deficient cells was also observed, but this amounted to only $41 \%$ of the increment in normal infected cells. Similar results were obtained regardless of whether the calculations were made per gram of hemoglobin or per $10^{9}$ red cells. It should also be noted that since both normal and G6PD-deficient erythrocytes were studied under conditions of nearly identical parasitemia (obtained by gelatin sedimentation) at particular stages of parasite development, variations in PRPP content cannot be attributed to different percentages of infected red blood cells or different stages.

PRPP synthetase activity. The large increase in PRPP content was not accompanied by a similar increase in PRPP synthetase enzyme (Table II). The results indicate that in all stages of parasite

Table II. PRPP Synthetase Activity of Normal and G6PD-deficient Human Erythrocytes Infected In Vitro with P. falciparum

\begin{tabular}{llll}
\hline & \multicolumn{2}{l}{ PRPP synthetase activity } \\
\cline { 2 - 3 } & Control & \multicolumn{1}{l}{ Rings $^{*}$} & Trophozoites $^{*}$ \\
\hline & $\mu m o l$ PRPP/g $H b / h$ & \\
Normal RBCs (5) & $56.8 \pm 15.3$ & $54.7 \pm 11.9$ & $46.7 \pm 13.6$ \\
G6PD- RBCs (3) & $55.7 \pm 14.3$ & $56.6 \pm 10.3^{*}$ & $58.2 \pm 10.7 \ddagger$
\end{tabular}

$\mathrm{RBC}$, red blood cell. Values are given as mean $\pm \mathrm{SD}$.

* Parasitemias are the same as in Table I.

‡ P-NS, normal vs. G6PD'. 
growth in both normal and G6PD-deficient red cells, the PRPP synthetase activity remains nearly constant throughout. Thus, the red cell-parasite unit increased PRPP content some 50-60fold without an increase in PRPP synthetase.

Incorporation of radiolabeled glucose into nucleic acids. Parasites growing in G6PD-deficient red cells displayed an abnormal incorporation pattern of $\left[{ }^{14} \mathrm{C}\right]$ glucose into nucleic acids (Table III). Whereas $\left[6-{ }^{14} \mathrm{C}\right]$ glucose was incorporated into nucleic acids preferentially in parasites growing in normal cells, there appeared to be no preference for $\left[6-{ }^{14} \mathrm{C}\right]$ glucose over $\left[1-{ }^{14} \mathrm{C}\right]$ glucose in the nucleic acids derived from parasites growing in G6PD-deficient red cells. The small difference $(7.1 \%)$ which is seen in G6PDdeficient infected red cells is not significant, whereas the difference $(18.4 \%)$ seen in parasites from normal red cells is significant at the $1 \%$ level. The extracted nucleic acids were shown by acrylamide gel electrophoresis to be of high molecular weight and purity (ratio O.D., 260:280 $\mathrm{nm}=2.2$ ), which permits comparisons of specific activity from differentially labeled glucose with confidence. Digestion of the nucleic acid preparation with RNA'ase demonstrated that $\sim 80 \%$ of the extracted nucleic acids consists of RNA, and the remainder of DNA.

Requirement of PRPP synthetase for GSH. Uninfected red cells can be selectively depleted of GSH by enzymatic conjugation with chlorodinitrobenzene which affects no other -SH group in either the red cell membrane or cytosol. Following partial or near total depletion of GSH (Table IV), there is a decreased ability of the red cell to synthesize PRPP from inosine. While inhibition of PRPP synthesis can be detected when GSH content falls to $50 \%$ of normal values, severe inhibition occurs only below this level. The data confirm the need of PRPP synthetase for GSH (19) and suggest a possible mechanism whereby PRPP synthesis may be blocked.

GSH content of $P$. falciparum-infected normal and G6PDdeficient red blood cells. Red cell GSH declined to a variable extent in both normal and G6PD-deficient red cells placed in culture (Table V). The decline is more severe in G6PD-deficient cells, and is most severe in G6PD Mediterranean red cells. It is of interest that there is little further decline in GSH levels produced by malaria infection. The severely GSH-depleted G6PDdeficient red cells clearly lack GSH as a cofactor for PRPP synthesis as well as for other functions where - $\mathrm{SH}$ group protection is afforded by GSH.

Pathways of PRPP synthesis. In close agreement with previously reported values (10), the PRPP content of freshly col-

Table III. Incorporation of Selectively Radiolabeled $\left[{ }^{14} \mathrm{C}\right]$ Glucose into Nucleic Acids of $P$. falciparum Cultured in Normal and G6PD-deficient Human Erythrocytes

\begin{tabular}{llll}
\hline & \multicolumn{2}{l}{ Nucleic acids } & \\
\cline { 2 - 4 } & $\begin{array}{l}{ }^{14} \mathrm{C}-1- \\
\text { glucose }\end{array}$ & $\begin{array}{l}{ }^{14} \mathrm{C}-6- \\
\text { glucose }\end{array}$ & $\begin{array}{l}\text { C-1-glucose } \\
\text { as percent } \\
\text { C-6-glucose }\end{array}$ \\
\hline & $c p m / \mu g$ & & \\
Normal & $377 \pm 36$ & $462 \pm 22 \ddagger$ & $81.6 \pm 5.7$ \\
G6PD $^{-}$ & $330 \pm 25$ & $355 \pm 21 \S$ & $92.9 \pm 2.3^{*}$ \\
\hline
\end{tabular}

Values are given as mean \pm SD.

* $P<0.01$; normal vs. G6PD .

$\ddagger P<0.01 ; \mathrm{C}$-1-glucose vs. C-6-glucose.

$\S P=$ NS; C-1-glucose vs. C-6-glucose.
Table IV. Effect of Low Red Blood Cell Reduced

GSH on PRPP Synthesis in Intact Normal

Human Erythrocytes Stimulated with Inosine

\begin{tabular}{|c|c|c|c|}
\hline & \multirow[b]{2}{*}{ GSH } & \multicolumn{2}{|l|}{ PRPP } \\
\hline & & Control & $\begin{array}{l}+5 \mathrm{mM} \\
\text { Inosine }\end{array}$ \\
\hline & $\mu \mathrm{mol} / \mathrm{g} \mathrm{Hb}$ & $\mathrm{nmol} / \mathrm{g} \mathrm{Hb}$ & \\
\hline 1. $n=5$ & $8.3 \pm 1.3$ & $199 \pm 67$ & $2,053 \pm 202$ \\
\hline 2. $n=5$ & $3.9 \pm 0.9$ & $195 \pm 82$ & $1,586 \pm 231^{*}$ \\
\hline 3. $n=5$ & $0.38 \pm 0.09$ & $94 \pm 41 \S$ & $341 \pm 23 \ddagger$ \\
\hline
\end{tabular}

Values are given as mean \pm SD.

$* P<0.051$ vs. 2 .

$\ddagger P<0.011$ vs. 3 .

$\S P<0.051$ vs. 3 .

GSH depletion was accomplished with chlorodinitrobenzene as described in Methods.

lected human red cells obtained in our laboratory is $5.6 \pm 0.72$ (SD) $\mathrm{nmol} / \mathrm{g} \mathrm{Hb}$. The baseline values described in these studies are often many times higher than the presumed in vivo values. This relates to the sensitivity of PRPP synthetase to inorganic phosphate content which is two- to threefold higher in culture medium than in blood. In some of the experiments with glycylglycine buffer, normal phosphate values are exceeded sixfold. Inorganic phosphate is known to be an important modulator of PRPP concentration (20). However, increases in inorganic phosphate mainly influence the activity of PRPP synthetase and do not preferentially influence any particular pathway of carbohydrate metabolism, although total glycolysis may be stimulated. Similarly, inosine is capable of raising red blood cell PRPP after cleavage of the ribose-phosphate moiety by nucleoside phosphorylase (Table IV) without directly affecting any pathway of glucose metabolism. Ascorbate incubation, on the other hand, augments pentose shunt activity in normal red cells

Table V. Reduced GSH Content of Normal and G6PD-deficient Human Erythrocytes Infected In Vitro with P. falciparum

\begin{tabular}{llll}
\hline & GSH & & \\
\cline { 2 - 3 } & Control & Infected & Parasitemia \\
\hline & $\mu$ mol/g $\mathrm{Hb}$ & & \\
Normals & 3.95 & & \\
& 8.98 & 3.49 & 81 \\
& 8.97 & 9.17 & 75 \\
& 4.70 & 6.63 & 80 \\
& 5.57 & 4.15 & 40 \\
Mean \pm SD & $6.43 \pm 2.38$ & $5.91^{*} \pm 2.24$ & $60 \pm 26$ \\
G6PD-deficient & $1.90 \S$ & 1.80 & 33 \\
& $0.00^{\prime \prime}$ & 0.00 & 30 \\
& $0.00^{\prime \prime}$ & 0.00 & 24 \\
Mean \pm SD & $0.63 \pm 1.10$ & $0.60 \ddagger \pm 1.03$ & $29 \pm 4.6$ \\
& & & \\
\hline
\end{tabular}

* $\ddagger P=\mathrm{NS}$; infected vs. control.

$\S$ G6PD A-African type.

"G6PD Mediterranean. 
and increases the production of ribose by oxidation of 6-phosphogluconate. Thus, in normal red cells, ascorbate stimulation of the pentose pathway increases PRPP content 10-fold, whereas stimulation of G6PD-deficient red cells produced only a twofold increase (Table VI).

\section{Discussion}

The impaired growth of $P$. falciparum in G6PD-deficient red cells has been explained by the lack of NADPH which drives the enzymatic reduction of oxidized glutathione, which in turn accumulates during exposure to oxidant stress. The present studies were undertaken to explore other possible consequences of the decreased pentose shunt activity in G6PD-deficient cells. The following new information has emerged from our studies: (a) $P$. falciparum growing in G6PD-deficient red cells have an abnormally decreased content of PRPP. (b) Infected G6PD-deficient red cells have decreased or absent reduced glutathione. (c) While PRPP synthetase enzyme quantity is not affected in G6PD-deficient red cells, the low content of GSH is likely to inhibit its activity. $(d) 18 \%$ of the glucose incorporated into nucleic acids by $P$. falciparum enters by way of the pentose shunt in normal red blood cells. In infected G6PD-deficient (Mediterranean) cells, virtually no glucose enters nucleic acids by this pathway. PRPP plays a key role in purine ribonucleotide metabolism and also participates in the synthesis of ribonucleotides of orotic acid and nicotinic acid (NAD and NADP) in mammalian cells (21). Stimulation of the pentose shunt is known to increase PRPP content (22), but attempts at pentose shunt stimulation in G6PD-deficient red cells fail to augment PRPP or purine nucleotide content (22). A block or even a partial block at this level of the metabolic pathway in rapidly proliferating cells is likely to have a material effect on growth rate. The lower PRPP levels seen in infected G6PD-deficient cells appears to be caused principally by the low GSH content and its effect on PRPP synthetase activity. The contribution of the pentose shunt to PRPP synthesis appears to be relatively minor. It appears, therefore, that low PRPP synthetase activity secondary to low GSH levels is the predominant cause of parasite growth inhibition in G6PD-deficient cells rather than the quantitatively smaller contribution of ribose-phosphate directly from hexose monophosphate shunt metabolism.

Further evidence of anomalous pentose metabolism in malaria-infected G6PD-deficient red cells is suggested by the finding of an abnormal labeling pattern of nucleic acids when prolif-

Table VI. Effect of Ascorbate-dependent Oxidative Stress on PRPP Production in Normal and G6PD-deficient Human Erythrocytes

\begin{tabular}{llll}
\hline & & \multicolumn{2}{l}{ PRPP } \\
\cline { 3 - 4 } & $\begin{array}{l}\text { G6PD } \\
\text { activity }\end{array}$ & Control & $\begin{array}{l}25 \mathrm{mM} \\
\text { Ascorbate }\end{array}$ \\
\hline & $I U / \mathrm{g} \mathrm{Hb}$ & $n \mathrm{nmol} / \mathrm{g} \mathrm{Hb}$ & \\
$\begin{array}{l}\text { Normals (4) } \\
\begin{array}{l}\text { G6PD } \\
\text { Deficient (4) }\end{array}\end{array}$ & $7.71 \pm 1.1$ & $355 \pm 131$ & $3300 \pm 554$ \\
\hline
\end{tabular}

Values are given as mean $\pm \mathrm{SD}$.

* $P=\mathrm{NS}$; G6PD deficient vs. normal.

$\ddagger P<0.001 ;$ G6PD deficient vs. normal. erating parasites are grown with selectively labeled glucose. If all of the ribose in parasite RNA and the deoxyribose in parasite DNA were derived from the pentose shunt, then none of the [1${ }^{14} \mathrm{Clglucose}$ label would have been incorporated into these nucleic acids. Instead, the radiolabeled carbon would have been released entirely as ${ }^{14} \mathrm{CO}_{2}$ by the oxidation of 6-phosphogluconate. Assuming no fixation of $\mathrm{CO}_{2}$, at least into nucleic acids, no radioactivity would have appeared in isolated RNA or DNA. The data, however, suggest that in normal infected cells, four of every five molecules of glucose incorporated into parasite nucleic acids were not derived from the oxidative portion of the pentose shunt pathway. This, in turn, suggests that the pentose shunt plays a role, but not a predominant one in nucleic acid synthesis. PRPP can arise (via ribose-5-phosphate): (a) from oxidation of 6-phosphogluconate with release of $\mathrm{CO}_{2}$ (reaction 1 ); $(b)$ by condensation of fructose-6-phosphate and glyceraldehyde-3-phosphate mediated by transaldolase and transketolase (reaction 2); (c) by phosphorolysis of inosine to its purine base and ribose-1-phosphate followed by isomerization to ribose-5-phosphate and thence to PRPP (23) (reaction 3). Stoichiometrically correct expressions of these reactions are:

$$
\begin{aligned}
& \text { Glucose-6-PO }{ }_{4}+2 \mathrm{NADP}^{+}+\mathrm{H}_{2} \mathrm{O} \stackrel{\text { G6PD/6PGD }}{\longrightarrow} \text { ribose-5- } \mathrm{PO}_{4} \\
& +2 \mathrm{NADPH}+2 \mathrm{H}^{+}+\mathrm{CO} 2
\end{aligned}
$$

2 fructose-6- $\mathrm{PO}_{4}$

+ glyceraldehyde-3- $\mathrm{PO}_{4} \stackrel{\text { transaldolase/transketolase }}{\longrightarrow} 3$ ribose-5- $\mathrm{PO}_{4}$

Inosine $\stackrel{\text { nucleoside phosphorylase }}{\longrightarrow}$ hypoxanthine

+ ribose-1- $\mathrm{PO}_{4} \stackrel{\text { Phosphoglucomutase }}{\longrightarrow}$ ribose-5- $-\mathrm{PO}_{4}$

The data obtained with specifically labeled $\left[{ }^{14} \mathrm{C}\right]$ glucose suggest that most of the PRPP is synthesized by the second pathway, the condensation of triose and fructose phosphates. This pathway does not require the first enzyme of the pentose shunt pathway and would incorporate radiolabeled C-1 or C-6 from glucose into pentose equally. The data obtained here are in agreement with Horecker's view of the Pentose shunt pathway (24). He has noted that in most mammalian systems, $75 \%$ of the pentose is obtained by the non-oxidative route (reaction 2 ). He, therefore, has viewed the C-1-gluoxidation pathway (reaction 1) not as part of a cycle, but as one of two parallel pathways in the formation of pentose phosphate from hexose phosphate. The special function of the less used oxidative pathway is for the generation of NADPH. The third method for synthesizing PRPP does not appear to be relevant to in vivo conditions, but remains a convenient method for manipulating cells in vitro and for demonstrating the functioning of nucleoside phosphorylase and PRPP synthetase.

Reitzer et al. (21) have recently considered the role of the pentose shunt in providing pentose phosphates for nucleic acids in HeLa cells. Of interest was their conclusion that the pentose shunt was not essential for the production of NADPH in HeLa cells (unlike the red cell). Instead, they pointed to its role as a source of pentose phosphate as the essential function of the shunt. The same authors also considered some of the potential errors in comparing the metabolic fates of C-1 vs. C-6 labeled glucose, and concluded that the extent of recycling of glucose and randomization of labels are not likely to lead to serious errors of interpretation by this method. The abnormal pattern of glucose 
metabolism found in infected G6PD-deficient red cells suggests that the parasites use the host cell metabolic machinery for much of its nucleic acid synthesis, at least as far as the carbohydrate contribution to that process is concerned. In the rear total absence of a pentose shunt (as seen in G6PD Mediterranean), virtually all the pentose in nucleic acids retains the ${ }^{14} \mathrm{C}-1$ from selectively labeled glucose. The possible presence of small quantities of parasite-derived G6PD (25) do not appear to have influenced the incorporation pattern of $\left[{ }^{14} \mathrm{C}\right]$ glucose. A definitive statement on this problem must await further studies on parasites which have been adapted to G6PD-deficient cells through several growth cycles.

The data presented here show that in normal human red cells, oxidative stress stimulates PRPP production by increasing shunt activity. Thus, parasite-related oxidant stress could benefit the parasite itself. In this regard, it is interesting to note that we have previously shown that GSH stability is enhanced in normal erythrocytes infected with $P$. falciparum (11). This finding implies that the parasite normally is prepared to handle increased oxidative stress while at the same time using the PRPP which may be generated by the increased pentose shunt activity which has been triggered by that same oxidant stress. GSH declines to the same extent in both infected and uninfected cells kept under culture conditions. Thus, no special parasite dependent oxidant stress need be involved.

How do these data relate to the previous explanations given for a selective advantage for G6PD deficiency in the face of potentially lethal malaria infection? The traditional interpretations rely on a decline in GSH content based on the inability of G6PD-deficient red cells to generate NADPH-an event which, in red cells, requires an intact pentose shunt together with an overwhelming oxidant stress. A significant oxidative stress, either created by the parasite itself or by some exogenous material, is always postulated, but rarely demonstrated (26). We and others have previously described a number of findings in normal infected red cells which suggest that the parasite/red cell unit is well protected against oxidative stress by enrichment with vitamin $\mathrm{E}$ and host superoxide dismutase as well as enhanced GSH stability $(27,28)$.

The explanation offered here, like the traditional one, is based on the lack of reduced glutathione, but in the present formulation, there is no need to invoke a co-existant oxidative stress; the reduction in GSH content has serious and pervasive deleterious consequences for parasite growth without requiring the cataclysmic destruction which is seen when oxidant drugs are given to malaria-bearing animals (26). A mechanism of this type has the advantage of being continuously active under all circumstances for each growth cycle of the parasite.

We previously documented a $50 \%$ inhibition of parasite growth $(3,29)$ in G6PD-deficient cells. There was no total block of parasite proliferation, but the lower in vivo parasitemias implied by this finding could certainly confer enhanced fitness on the bearer of G6PD-deficient red cells. The biochemical data provided here are clearly consistent with the degree of growth inhibition which we have observed and affirm the role of G6PD deficiency as a potent malaria resistance factor.

\section{Acknowledgments}

We thank Dr. Ronald L. Nagel for helpful discussions and advice. This work was supported by National Institutes of Health grants HL 21016 and AI24029, and a grant from the Howard Gilman Foundation.

\section{References}

1. Motulsky, A. G. 1960. Metabolic polymorphisms and the role of infectious diseases in human evolution. Hum. Biol. 32:28-62.

2. Friedman, M. J., E. F. Roth, Jr., R. L. Nagel, and W. Trager. 1979. Plasmodium falciparum: physiological interactions with the human sickle cell. Exp. Parasitol. 47:73-80.

3. Roth, E. F., Jr., C. Raventos-Suarez, A. Rinaldi, and R. L. Nagel. 1983. Glucose-6-phosphate dehydrogenase deficiency inhibits in vitro growth of plasmodium falciparum malaria. Proc. Natl. Acad. Sci. USA. 80:298-299.

4. Luzzatto, L., O. Sodeinde, and G. Martini. 1983. Genetic variation in the host and adaptive phenomena in Plasmodium falciparum growth by glucose-6-phosphate dehydrogenase deficient red cells. Ciba Found. Symp. 94:159-173.

5. Friedman, M. J. 1979. Oxidant damage mediates variant red cell resistance to malaria. Nature (Lond.). 280:245-246.

6. Pollack, A. S., J. N. George, and W. H. Crosby. 1966. Effects of agents simulating the abnormalities of the glucose-6-phosphate dehydrogenase deficient red cell on Plasmodium berghei malaria. Nature (Lond.). 210:33-35.

7. Golenser, J., J. Miller, D. T. Spira, T. Navok, and M. Chevion. 1983. Inhibitory effect of a fava bean component on the in vitro development of $P$. falciparum in normal and G6PD deficient erythrocytes. Blood. 61:507-510.

8. Jensen, J. B., and W. Trager. 1977. P. falciparum in culture: use of outdated erythrocytes and description of the candle jar method. $J$. Parasitol. 63:883-886.

9. Jensen, J. B. 1978. Concentration from continuous culture of erythrocytes infected with trophozoites and schizonts of Plasmodium falciparum. Am. J. Trop. Med. Hyg. 27:1274-1276.

10. Tax, W. J. M., and J. H. Veerkamp. 1977. A simple and sensitive method for estimating the concentration and synthesis of 5-phosphoribosyl-1-pyrophosphate in red blood cells. Clin. Chim. Acta. 78:209-216.

11. Roth, E. F., Jr., C. Raventos-Suarez, M. Perkins, and R. L. Nagel. 1982. Glutathione stability and oxidative stress in $P$. falciparum infection in vitro: responses of normal and G6PD deficient cells. Biochem. Biophys. Res. Commun. 109:355-362.

12. Moroney, M. J. 1956. In Facts from Figures. 3rd ed. Pelican Books, Ltd., Harmondsworth, Middlesex, England. 216-238.

13. Jaffe, E. R. 1969. In Biochemical Methods in Red Cell Genetics. J. J. Yunis, editor. Academic Press, New York. 239.

14. Awasthi, Y. C., H. S. Garg, D. D. Dao, C. A. Partridge, and S. K. Srivastava. 1981. Enzymatic conjugation of erythrocyte glutathione with 1-chloro-2,4-dinitrobenzene: the fate of glutathione conjugate in erythrocytes and the effect of glutathione depletion on hemoglobin. Blood. 58:733-738.

15. Beutler, E. 1975. Red Cell Metabolism: a manual of biochemical methods. Grune \& Stratton, New York. 112-113.

16. Sandberg, A. A., G. R. Lee, G. E. Cartwright, and M. M. Wintrobe. 1955. Purine nucleoside phosphorylase activity in blood. J. Clin. Invest. 34:1823-1829.

17. Klenow, H., and B. Larsen. 1952. The action of phosphoglucomutase preparations on ribose-1-phosphate. Arch. Biochem. Biophys. 37:488-489.

18. Beutler, E., K. G. Blume, J. C. Kaplan, G. W. Lohr, B. Ramot, and W. N. Valentine. 1977. International committee for standardization in hematology: recommended methods for red cell enzyme analysis. $\mathrm{Br}$. J. Haematol. 35:331-340.

19. Zoref, E., A. DeVries, and O. Sperling. 1975. Mutant feedbackresistant phosphoribosyl-pyrophosphate synthetase associated with purine overproduction and gout. J. Clin. Invest. 56:1093-1099.

20. Raivio, K. O., C. S. Lazar, and M. A. Becker. 1981. Regulation of 5-phosphoribosyl-1-pyrophosphate synthesis in human fibroblasts by the concentration of inorganic phosphate. Biochim. Biophys. Acta. 678: 58-64.

21. Reitzer, L. J., W. M. Burton, and D. Kendall. 1980. The pentose 
cycle: control and essential function in HeLa cell nucleic acid synthesis. J. Biol. Chem. 255:5616-5626.

22. Yeh, G. C., E. F. Roth, Jr., J. M. Phang, S. C. Harris, R. L. Nagel, and A. Rinaldi. 1984. The effect of pyrroline-5-carboxylic acid on nucleotide metabolism in erythrocytes from normal and glucose-6phosphate dehydrogenase deficient subjects. J. Biol. Chem. 259:5454 5458.

23. Stryer, L. 1975. In Biochemistry. 2nd ed. W. H. Freeman and Co., San Francisco, CA. 333-340.

24. Horecker, B. L. 1965. Pathways of carbohydrate metabolism and their physiological significance. J. Chem. Educ. 42:244-253.

25. Usanga, E. A., and L. Luzzatto. 1985. Adaptation of Plasmodium falciparum to glucose-6-phosphate dehydrogenase deficient host red cells by production of a parasite encoded enzyme. Nature (Lond.). 313:793795.

26. Clark, I. A., W. B. Cowden, N. H. Hunt, L. E. Maxwell, and
E. J. Mackie. 1984. Activity of divicine in Plasmodium vinckei infected mice has implications for treatment of favism and the epidemiology of glucose-6-phosphate dehydrogenase deficiency. Br. J. Haematol. 57:479487.

27. Roth, E. F., Jr., C. Raventos-Suarez, H. Gilbert, D. Stump, H. Tanowitz, K. S. Rowin, and R. L. Nagel. 1984. Oxidative stress and falciparum malaria: a critical review of the evidence. In Malaria and the Red Cell. J. Eaton and G. Brewer, editors. Alan R. Liss, Inc., New York. 35-43.

28. Fairfield, A. S., S. R. Meshnick, and J. W. Eaton. 1983. Malaria parasites adopt host red cell superoxide dismutase. Science (Wash. DC). 221:764-766.

29. Roth, E. F., Jr., C. Raventos-Suarez, A. Rinaldi, and R. L. Nagel. 1983. The effect of $X$ chromosome inactivation on the inhibition of Plasmodium falciparum malaria growth by glucose-6-phosphate dehydrogenase deficient red cells. Blood. 62:866-868. 